\title{
AI-Audit: The Perspectives of Digital Technology Application in the Audit Activity
}

\author{
Vilena Anatol'evna Yakimova \\ Department of Finances \\ Amur State University \\ Blagoveshchensk, Russia \\ vilena_yakimova@mail.ru
}

\begin{abstract}
The analysis of IT evolution is made in the article and possibilities and perspectives of digital technology application for the execution of the cognitive processes are described. The system of the interlinked AI-technologies is developed and suggested and their applied application in the audit is described. Digital technologies of AI, descriptive and predictive analysis of a big data can find an application aspect in the digitalization of audit activity that will contribute to the acceleration of the data mining, the transition from the manual performance of procedures to the machine processing of information, algorithmization of the planning and deep understanding of the activity of the audited people.
\end{abstract}

Keywords: digital economy, digital technologies, audit services, intellectual audit, AI technologies, cognitive processes

\section{INTRODUCTION}

The peculiarity of digital economy is the introduction of more productive digital technologies into the economic activity of different economic entities that will contribute to the information pro-cesses of mining, processing and data transfer. Under the conditions of digitalization whole new models of an activity arrangement and mutual relations between economic subjects and society are formed. In September, 2016 the working group of the International Auditing and Assurance Stand-ards Board (IAASB) recommended auditors to apply digital technologies (AIsystems with the technologies for the analysis of a big dataData Analytics) with the purpose of audit quality improvement and minimization of detection risk. Audit companies of Big 4 adapting to the modern digital environment apply innovative technologies for the execution of certain auditing processes but the projects are not systembased and far from being perfect. At present the emerging market of data technologies allows developing applied information products for audit companies. Meanwhile the main task for the development of complex solutions is the selection of tasks and domain defini-tion of digital technologies application. The purpose of the research is the project development of AI-audit as the system of digital technologies aimed at the realization of cognitive processes of au-dit activities based on the analysis and systematization of the main trends of applied digital technol-ogies development.

\section{REVIEW OF SCIENTIFIC LITERATURE ON RESEARCH}

Under the conditions of digital economy shaping the traditional model of audit activities is transformed into the model of intelligent audit "AI-audit". Its informationtechnological provision is based on artificial intelligence technologies for the cognitive tasks at all stages of financial audit. AI-audit is semi digital set of technologies (intelligent data analysis, speech recognition, machine learning, pictures and sentiment analysis) that complete and advance processes of audit activities [Ukpong, 2019]. Under the conditions of digital economy applied AI-technologies appeared that can be used in the practical audit activities: expert systems, genetic programming, neural networks, fuzzy and hybrid systems [Baldwin, 2006]. Such technologies are aimed at the simplification of cognitive problems solution that traditionally are posed for a man auditor. They include, for exam-ple, an algorithm development, comprehension of abstract concepts, memorization of experience, monitoring, project development and forecasting, critical evaluation of audit evidence, risk assess-ment and systems of internal control, data processing and generation. The research conducted by the foreign scholars (M.J. Abdolmohammadi, 1987; S.E. Bonner et al., 1991) allowed categorizing cognitive processes in audit according to the formality as routine and structured, semi structured (an algorithm is assigned but the problem is solved under uncertainty) and unstructured. Unstructured cognitive processes require an original algorithm design of the solution depending on a particular situation under uncertainty and dynamism of source data and knowledge (interpretation, diagnos-tics, planning, self-study, clusterisation, decisionmaking). The majority of the procedures in audit is unstructured and contains a lot of alternative variants and ways of solution that requires working out of the professional judgment [Commerford, 2019]. Formalized approach application in audit can lead to the growth of detection risk of fraud schemes and possibility of contradictory and suspicious evidence omission. AI-technologies relying on the models 


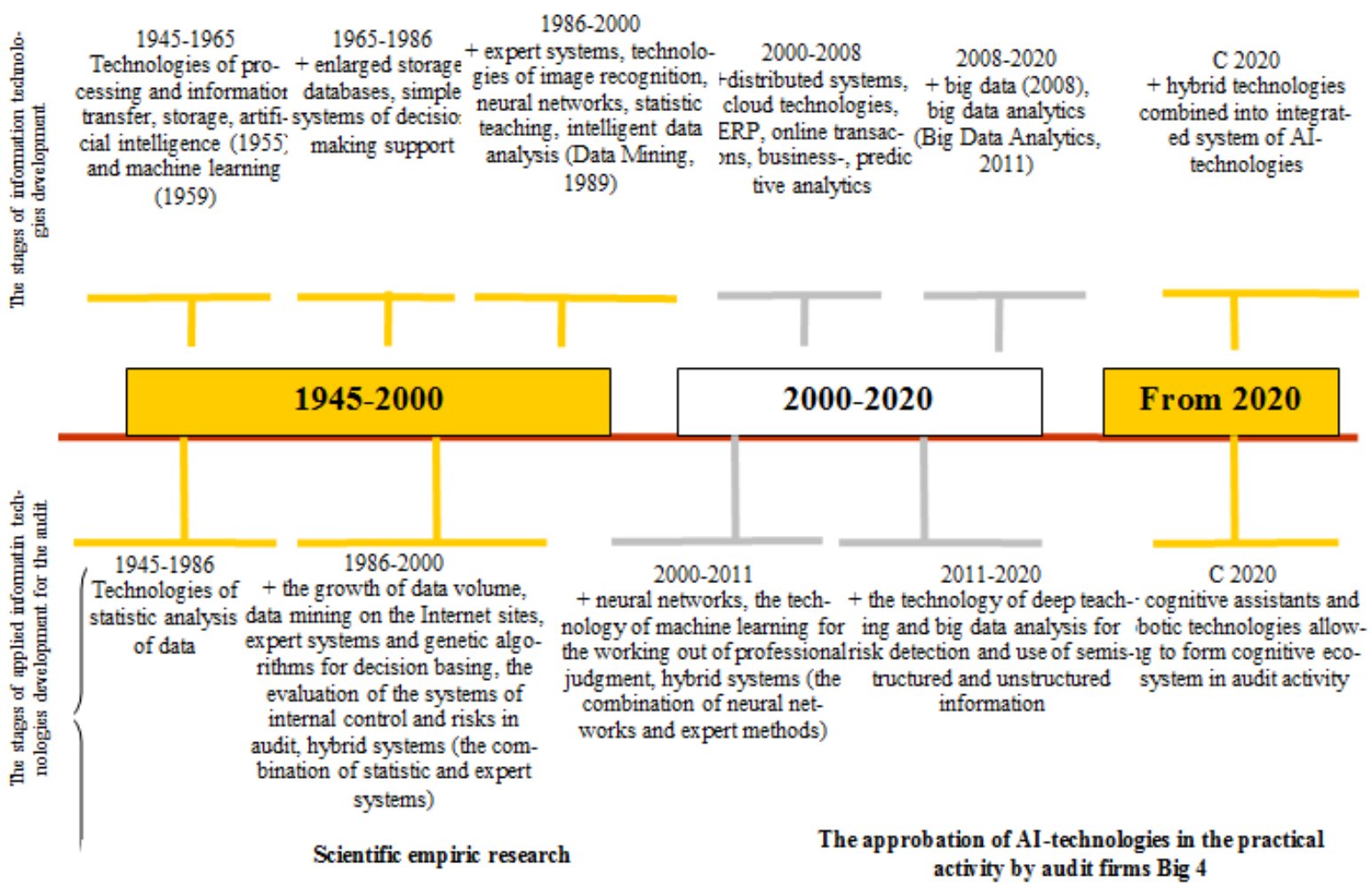

Fig. 1. The evolution of information technologies and their application in audit activity

with fuzzy logic, methods of evolutionary computation, neural networks allow hypothesizing based on the judgments, mining data from separate including unstructured sources of information. They also help to analyze information of large amount and visualize the results of the analysis and evaluate supported evidence. The transi-tion to the AI-audit is preceded by a long period of information technologies development and their application in audit activity which can be divided into three stages (fig. 1).

Under the conditions of information mining the critics of statistic models for audit, the growth of business risks diversity in the changeable economic environment contributed to the tran-sition from the application of information technologies of statistic data processing to the cognitive technologies. The first AI-technologies applied in audit were expert systems which allowed mining and systematizing professional knowledge, working out solutions of intellectual tasks and explain-ing the mechanism of solution on the user's query. The expert model of the internal control system evaluation was suggested in 1986 by R.D. Meservey et al., the evaluation model of auditor's evi-dence in 1990 - by J.E. Boritz et al., M.M. Eining and D.R. Jones developed expert system for the detection of fraud risks in 1997. The expert systems allowed working out the effective mechanism of organizational and managerial decisions justification made by the auditor on the basis of the pos-sible alternative variants generation. In the research O.J. Welch describes the algorithms and patterns of auditor's behavior when detecting fraud risks [Welch, 1998]. For the going-concern assessment of the audited organization activity M. J. Lenard et al. develop genetic software. The basis of it was methods of fuzzy sets, expert assessment and statistic models [Lenard, 2001]. In the beginning of XXI neural networks were developed for the creation of self -study AI-system which contains knowledge base as a large set of empiric data. With the reference to audit the teaching selection is the set of data with marks formed on the basis of the previous experience of audit examination, typical cases set and solution algorithms of different practical situations. J. Perols, C. Brandas et al. applied methods of machine learning to create the system which allows detecting the facts of fraud based on the search of atypical elements deviating from standard data [Perols, 2011], [Brandas, 2018]. E. Koskivarra suggested applying methods of intelligent data analysis for examination procedures, Calderonand et al. - for risk assessment, H. Koh - for the examination of the going con-cern principle observance of the audited person's activity.

The contemporary research in the area of information technologies application in audit show that under the conditions of large amounts of information and the necessity of its processing in the shortest time, the integration of structured and unstructured data into the traditional audit is impos-sible. The potential expansion of the digital economy allows implementing method of big data ana-lytics into audit activity [Kokina, 2017], [Li, 2018]. In the course of the research $\mathrm{H}$. Issa et al. made a conclusion about the necessity of a deep neural network combination for the analysis of data from social networks, videotape recordings, press-releases, news, processing and recognition of text and images of documents as hard copies [Issa, 2016]. Big data technology is based on methods of lin-guistic analysis that allows performing an analysis of the documents contents, sites and detecting the emotional coloring of the text. T. Sun, M.A. 
Hybrid intelligent systems (expert systems, neural networks, machine vision, machine learning, cloud technologies etc.)

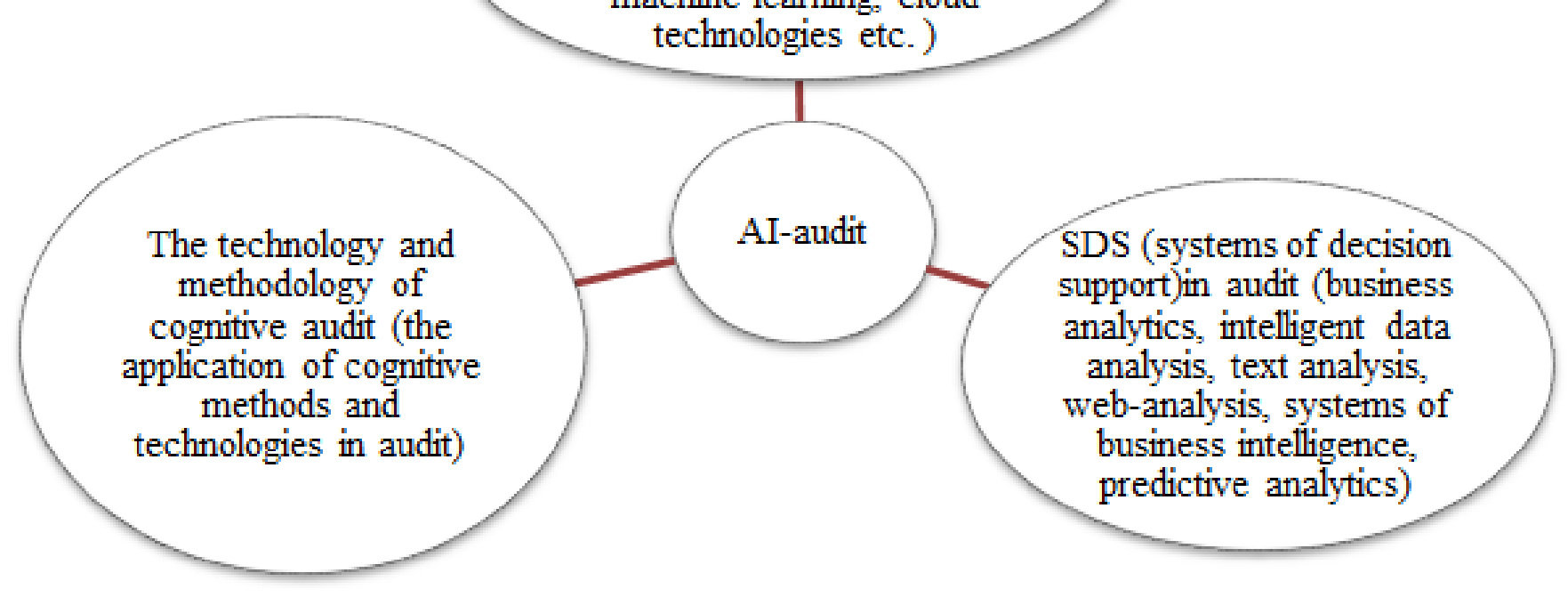

Fig. 2. The suggested system of AI-technologies for the audit activity

Vasarhelyi examine applied aspects of text infor-mation analysis (Text Mining) as a kind of big data for the mining and data processing, and in the works of N. Hashimzade, R. Fay et al. - predictive analytics for the risk assessment [Sun, 2018; Hashimzade, 2016; Fay, 2017].

\section{RESULTS OF AI-TECHNOLOGIES APPLICATION IN THE AUDITOR ACTIVITY}

As perspective directions of applied AI-technologies development and their use in the practi-cal activity of audit organizations we should consider the formation of a cognitive ecosystem and creation of intelligent assistants as a complex of interconnected AI-technologies. Intelligent assistant for audit organization (Intelligent Personal Assistants (IPA) is a software complex performing a set of operations of audit examination autonomously and on the user's requirement based on the principles of argumentation and implementation of other cognitive functions [Brandas, 2018].

Q. Li, M. Vasarhelyi mention that cognitive assistants are "technologies with the manipulation of a natural language and interactive support of decision making for the retrieval and search of relevant information, planning and risk assessment which allow understanding voice commands and answering questions in the most convenient way" [Li, 2018]. From our view the perspective cogni-tive ecosystem of audit activity should include the ensemble of intelligent systems, methods of knowledge base creation, the management of knowledge and cognitive technologies. They are in interaction and aimed at the execution of cognitive processes in audit providing the formation of professional opinion when facilitating audit services and delivering related to audit services.

The cognitive ecosystem of audit activity should contain the following subsystems:
1. intelligent subsystem as a basic complex of softwarehardware;

2. subsystem of AI-technologies;

3. subsystem of knowledge management mining knowledge base in the sphere of auditor's activity.

Under the interaction of the first and second subsystem hybrid intelligent systems for the audit appeared which are described in scientific research and aimed at the solution of particular tasks. The integration of the first and third areas allows forming applied technologies of the decision-making support systems, the second and the third - the technology and methodology of the cognitive audit (fig. 2).

The system of AI-technologies for the audit activity should contribute to the execution of such cognitive processes as input and information recognition; teaching, introduction and accumula-tion of knowledge; analytic processing of information; management; formation of judgments, conclusions and opinions. During the research the analysis was made in the context of detailed cogni-tive processes and possibilities of digital technologies application are detected (table 1).

For the execution of input and information recognition process it is necessary to make natu-ral-language interface which helps to computerize the collection of financial and nonfinancial and also visual and acoustic information, its' grouping according to the verification directions. There are solutions to experimental problems in this area that are applied by audit companies of Big 4. From 2016 AI-technologies began to be applied for the retrieval of information and recognition of details and other symbols of accounting documents. For example, Deloitte introduced AI-product Argus on the basis of Kira Systems, KPMG applies IBM 

PROCESSES

\begin{tabular}{|c|c|c|c|c|c|c|c|c|c|c|}
\hline & & \multirow[b]{2}{*}{$\begin{array}{c}\text { The } \\
\text { process } \\
\text { of } \\
\text { teachin } \\
\text { g, } \\
\text { submiss } \\
\text { ion and } \\
\text { accumu } \\
\text { lation of } \\
\text { knowle } \\
\text { dge }\end{array}$} & \multicolumn{6}{|c|}{ The process of analytic handling of information } & \multirow[b]{2}{*}{$\begin{array}{l}\text { The } \\
\text { process of } \\
\text { manageme } \\
\text { nt and } \\
\text { decision- } \\
\text { making }\end{array}$} & \multirow[b]{2}{*}{$\begin{array}{c}\text { The } \\
\text { process of } \\
\text { working } \\
\text { out of } \\
\text { profession } \\
\text { al opinion }\end{array}$} \\
\hline & & & $\begin{array}{c}\text { The } \\
\text { assessme } \\
\text { nt of } \\
\text { business } \\
\text { risks of a } \\
\text { potential } \\
\text { client } \\
\text { when } \\
\text { providin } \\
\text { g access } \\
\text { to service }\end{array}$ & $\begin{array}{c}\text { Analytical } \\
\text { procedures for } \\
\text { the } \\
\text { comprehensio } \\
\text { n of activity, } \\
\text { risk } \\
\text { assessment, } \\
\text { business going } \\
\text { concern }\end{array}$ & $\begin{array}{c}\text { The } \\
\text { asses } \\
\text { smen } \\
\text { t of } \\
\text { impo } \\
\text { rtanc } \\
\text { e }\end{array}$ & $\begin{array}{c}\text { Testi } \\
\text { ng of } \\
\text { cont } \\
\text { rols }\end{array}$ & $\begin{array}{c}\text { The } \\
\text { collection } \\
\text { and } \\
\text { checking of } \\
\text { informatio } \\
\text { n about } \\
\text { affiliated } \\
\text { persons } \\
\text { and } \\
\text { transaction } \\
\text { s with them }\end{array}$ & $\begin{array}{c}\text {.Related } \\
\text { to audit } \\
\text { services: } \\
\text { investme } \\
\text { nt audit. } \\
\text { Audit of } \\
\text { prospecti } \\
\text { ve } \\
\text { informat } \\
\text { ion etc. }\end{array}$ & & \\
\hline \multicolumn{11}{|c|}{ Hybrid intelligent systems: } \\
\hline expert systems & $*$ & $*$ & - & - & - & - & - & - & $*$ & * \\
\hline neural networks & $*$ & $\checkmark$ & - & - & - & - & - & - & $\checkmark$ & $\checkmark$ \\
\hline $\begin{array}{l}\text { machine vision (incl. } \\
\text { drones) }\end{array}$ & $\checkmark$ & $\checkmark$ & - & - & - & - & - & - & - & - \\
\hline machine learning & $*$ & $*$ & - & - & - & - & - & - & $\checkmark$ & $\checkmark$ \\
\hline cloud technologies & $*$ & $*$ & - & - & - & - & - & - & $*$ & - \\
\hline \multicolumn{11}{|c|}{ The systems of decision support in the audit: } \\
\hline business-analytics & - & - & $*$ & $*$ & $\sqrt{ }$ & $\checkmark$ & * & $*$ & $*$ & $\checkmark$ \\
\hline $\begin{array}{l}\text { intelligent analysis of } \\
\text { data }\end{array}$ & - & - & $*$ & $\checkmark$ & $\checkmark$ & $\checkmark$ & $\checkmark$ & $\checkmark$ & $\checkmark$ & $\checkmark$ \\
\hline text analysis & - & - & $\checkmark$ & $*$ & $\checkmark$ & $\checkmark$ & $\checkmark$ & $\checkmark$ & $\checkmark$ & $\checkmark$ \\
\hline web-analysis & - & - & $\checkmark$ & $*$ & $\checkmark$ & $\checkmark$ & $\checkmark$ & $\checkmark$ & $\checkmark$ & $\checkmark$ \\
\hline $\begin{array}{c}\text { systems of business- } \\
\text { intelligence }\end{array}$ & - & - & $\checkmark$ & $\checkmark$ & $\checkmark$ & $\checkmark$ & $\checkmark$ & $\checkmark$ & $\checkmark$ & $\checkmark$ \\
\hline predictive analytics & - & - & $\checkmark$ & $\checkmark$ & $\checkmark$ & $\checkmark$ & - & $\checkmark$ & $\checkmark$ & $\checkmark$ \\
\hline
\end{tabular}

${ }^{\text {a. }}$ Keys: $*$ there are solutions to experimental problems; $\checkmark$ there is a potential for development in the future; $\checkmark$ the perspective areas of AI-technologies application in audit

Watson Natural Language Understanding for deep learning, and for the search from open data sources - Tensor Flow and Theano. The chief executive of Deloitte C. Angelbert mentions the possibility of drone application developed on the basis of machine vision to observe inventory and assess the actual asset availability in their locations. Under the conditions of data technologies implementation the firm can get some effect from labor cost reduction for the collection and information processing as technologies allow reading of 800 mln. pages per second. Machine learning technologies and algorithms of knowledge base creation are applied to implement the learning process, for the submission and accumulation of knowledge. The knowledge base consists of a set of facts describing a subject area of examination, rules and procedures of their logical processing, base patterns and designed for making conclusions and new knowledge generation. For the formation of judgments, conclusions and decisions in AI-system of audit activity the methods of technical, semantic and logic information processing should be used. In this area the companies of Big 4 have solutions to experimental problems but none of AI-systems in audit is self learning.

The process of analytical information processing is based on the technologies of retrieval and analysis of small information (limited by the information base of an audited person) and big data. In audit and in the provision of related services analytical procedures were developed for planning, business risks assessment, confirmation of conditions for business going concern, identification of errors and distortions, fraud and when expressing an opinion in an auditor's report. The technologies of text analysis and web analysis are necessary in audit for risk assessment of the client's commercial goodwill loss and honesty of an audited person, his management at the stage of planning and decision making about customer service. Watson Analytics uses technologies which allow providing a user with the information about positive and negative reviews on the Internet about the activity of an audited person, his authorities and output product. For the analysis of a Big Data and assessment of risk factors Big 4 companies use analytical platforms Halo (PWC), Optix (Deloitte), KRisk (KPMG). The perspective area of digital data application is the broadening of the related services range with the help of intelligent data analysis methods and application of predictive analytics methods. AI-technologies can help to discover factors that influence an audited person: an economic slump in the country, in the industry, region, currency devaluation, bankruptcy of key raw material suppliers, the loss of sales markets and the emergence of successful competitors on the market. Artificial Intelligence can identify patterns, correlation relationships between the index of audited people similar in type and scale of activity.

The cognitive processes of audit companies' management are processes of planning of the character, scope and time frame of procedures, selection of auditor's actions as the response to risk assessment and evidence. They also include 
[6] R.D. Meservey, Jr.A.D. Bailey, and P.E. Johnson, "Internal control

percent selection and benchmark for the calculation of materiality considering the knowledge about the type of audited organization, the structure of prop-erty and financing method. System decisions for the execution of such processes in the practical ac-tivity have not implemented yet and require additional developments. For the organization and business management the perspective area of digital technologies application is "online-audit" or "going concern audit". It allows executing examination procedure in real time mode and carrying out the procedures of monitoring and quality test time efficient.

\section{DISCUSSION AND CONCLUSION}

Thereby under the conditions of digital economy new possibilities are created for the devel-opment and introduction of intelligent technologies that help to increase the efficiency of examina-tion process and to ensure quality of audit services. AI-technologies allow analyzing information in real time mode, selecting automatically or suggesting a choice of alternative procedures. They also help to correct the program of examination if it is necessary and respond to an elevated level of au-dit risk. The challenge of an auditor in a cognitive ecosystem is in machine learning, adequacy as-sessment, the materiality of the selected information for the system training and interpretation of distortions identified by technologies.

\section{References}

[1] E.G. Ukpong, I.I. Udoh, and I.T. Essien, "Artificial Intelligence: Opportunities, Issues and Applications in Accounting and Auditing in Nigeria", Asian Journal of Economics, Business and Accounting, 10 (1), pp. 1-6, 2019.

[2] A.A. Baldwin, C.E. Brown, and B.S. Trinkle, "Opportunities for artificial intelligence development in the accounting domain: the case for auditing", Intelligent Systems in Accounting, Finance \& Management: International Journal, vol. 14 (3), pp. 77-86, 2006.

[3] M.J. Abdolmohammadi, "Decision support and expert systems in auditing: a review and research directions", Accounting and Business Research (Spring), vol. 17, pp. 173-185, 1987.

[4] S.E. Bonner and N. Pennington, "Cognitive processes and knowledge as determinants of auditor expertise", Journal of Accounting Literature, vol. 10, pp. 1-50, 1991.

[5] B.P. Commerford, S.A. Dennis, J.R. Joe, and J. Wang, "Complex Estimates and Auditor Reliance on Artificial Intelligence", 2019 [Electronic resource]. Available at: https://ssrn.com/abstract=3422591. evaluation: a computational model of the review process", Journal of Practice and Theory, vol. 6 (1), pp. 44-74, 1986.

[7] J.E. Boritz and A.K.P. Wensley, "Structuring the assessment of audit evidence - an expert systems approach", Journal of Practice and Theory, vol. 9, pp. 49-98, 1990.

[8] M.M. Eining and D.R. Jones, "Reliance on decision aids: an examination of auditors' assessment of management fraud", Journal of Practice and Theory, vol. 16 (2), pp. 1-19, 1997.

[9] O.J. Welch, T.E. Reeves, and S.T. Welch, "Using a genetic algorithmbased classifier system for modeling auditor decision behavior in a fraud setting", International Journal of Intelligent Systems in Accounting, Finance and Management, vol. 7, pp. 173-186, 1998.

[10] M.J. Lenard, P. Alam, D. Booth, G. Madey, "Decision-making capabilities of a hybrid system applied to the auditor's going-concern assessment", International Journal of Intelligent Systems in Accounting, Finance and Management, vol. 10, pp. 1-24, 2001.

[11] J. Perols, "Financial Statement Fraud Detection: An Analysis of Statistical and Machine Learning Algorithms", Journal of Practice \& Theory, vol. 30, no. 2, pp. 19-50, 2011.

[12] C. Brandas, M. Muntean, and O. Didraga, "Intelligent decision support in auditing: Big Data and machine learning approach", 17th International Conference on Informatics in economy, IE 2018, Education, Research \& Business Technologies, The Bucharest University of Economic Studies, Bucharest, Romania, pp. 425-430, 2018.

[13] E. Koskivaara, "Artificial neural network models for predicting patterns in auditing monthly balances", Journal of the Operational Research Society, vol. 51, pp. 1060-1069, 2017.

[14] H.C. Koh, "Going concern prediction using data mining techniques", Managerial Accounting Journal, 19 (3), pp. 462-476, 2004.

[15] J. Kokina and Th.H. Davenport, "The Emergence of Artificial Intelligence: How Automation is Changing Auditing", Journal of emerging technologies in accounting, vol. 14, no. 1, pp. 115-122, 2017.

[16] H. Issa, T. Sun, and M.A. Vasarhelyi, "Research Ideas for Artificial Intelligence in Auditing: The Formalization of Audit and Workforce Supplementation", Journal of Emerging Technologies in Accounting, vol. 13 , no. 2 , pp. 1-20, 2016.

[17] T. Sun and M.A. Vasarhelyi, "Embracing Textual Data Analytics in Auditing with Deep Learning", The International Journal of Digital Accounting Research, vol. 18, pp. 49-67, 2018.

[18] N. Hashimzade, G.D. Myles, and M.D. Rablen, "Predictive Analytics and The Targeting of Audits", Journal of Economic Behavior \& Organization, vol. 124, pp. 130-145, 2016.

[19] R. Fay and E.M. Negangard, "Manual Journal Entry Testing: Data Analytics and The Risk of Fraud", Journal of Accounting Education, vol. 38, pp. 37-49, 2017.

[20] Q. Li and M.A. Vasarhelyi, "Developing a Cognitive Assistant for the Audit Plan", The International Journal of Digital Accounting Research, vol. 18, pp. 119-140, 2018. 